\title{
Protagonismo Guarani na porção sul do Brasil Meridional: o ñande reko em territórios das bacias hidrográficas dos rios Iequí e Caií no ano de $1635^{1 *}$
}

\author{
Guarani protagonism in the southern portion of Southern Brazil: the \\ nande reko in territories of hydrographic basis of the rivers Iequi and \\ Cail in the year 1635
}

Tuani de Cristo $^{2}$

Luís Fernando da Silva Laroque ${ }^{3}$

Neli Teresinha Galarce Machado ${ }^{4}$

RESUMO

No século XVII, a Companhia de Jesus adentrou áreas do atual Estado do Rio Grande do Sul, incursionando pelas bacias hidrográficas dos rios lequí (Pardo) e Caii (Caí), onde parcialidades Guarani estabeleceram alianças com os jesuítas. Contudo, nem todos os Guarani aceitaram o projeto colonial, a exemplo das lideranças espirituais, que refutaram aproximações com os padres. O objetivo do estudo é analisar a atuação de lideranças, tais como, a Tayubai e a Apyçaire, que declararam guerra aos padres em nome do nãnde reko Guarani, em territórios dos rios lequí e Caií, no ano de 1635. A metodologia é qualitativa e descritiva, fundamentada na abordagem etno-histórica, para análise da Carta Ânua de 1635. O trabalho analisa dois eventos ocorridos próximos às reduções jesuíticas do rio lequí e em territórios do rio Caii, quando parcialidades Guarani entraram em conflito com os jesuítas. No primeiro evento, o padre Mendonza é assassinado por parcialidades lideradas por Tayubai; no segundo evento, outras parcialidades atacaram a redução de Jesus Maria, no rio lequí. Em vista disso, constata-se que nem todos

\footnotetext{
${ }^{1} \mathrm{O}$ estudo insere-se no Projeto de Pesquisa "Arqueologia, História Ambiental e Etnohistória do RS", vinculados ao PPG em Ambiente e Desenvolvimento e conta com auxílios financeiro da Universidade do Vale do Taquari - UNIVATES e do CNPq.

${ }^{2}$ Mestranda no Programa de Pós-Graduação em Ambiente e Desenvolvimento (Bolsista PROSUC/CAPES), Universidade do Vale do Taquari - UNIVATES. e-mail: tuanidecristo@gmail.com

${ }^{3}$ Doutor em História. Professor do Curso de Licenciatura em História e do Programa de Pós-Graduação em Ambiente e Desenvolvimentos, Universidade do Vale do Taquari - UNIVATES. e-mail: lflaroque@univates.br

${ }^{4}$ Doutora em Aqueologia. Professora do Curso de Licenciatura em História e do Programa de Pós-Graduação em Ambiente e Desenvolvimentos, Universidade do Vale do Taquari - UNIVATES. e-mail: ngalarce@univates.br
} 
os indígenas Guarani aceitaram os jesuítas nas proximidades de seus territórios, pois avaliaram o contato a partir de seus parâmetros culturais, não concordando com os ensinamentos dos padres.

Palavras-chave: Guarani. Protagonismo. Ñande reko. Jesuítas. Lideranças.

\section{ABSTRACT}

In the 17th century, the Society of Jesus entered areas belonging to the current Brazilian state of Rio Grande do Sul, entering the river basins of the lequí (Pardo) and Caii (Caí), where Guarani partialities established alliances with Jesuits. However, not every Guarani accepted the colonial project, like the spiritual leaderships who refuted approaches with the priests. The goal of this study is to analyze the performance of leaderships such as Tayubai and Apyçaire who declared war on the priests in the name of the ñande reko Guarani in territories of the rivers lequí and Caii in the year 1635. The methodology is qualitative and descriptive, based on the ethno-historical analysis of the 1635 Ânua. The paper analyzed two events that occurred next to the Jesuit reductions of the lequí river and in the territories of the Caii river, when Guarani parties clashed with the Jesuits. In the first event, priest Mendonza is assassinated by partialities led by Tayubai, in the second event other partialities attacked the reduction of Jesus Maria in the lequí river. In view of this, it was found that not all Guarani natives accepted the Jesuits near their territories, because they evaluated the contact from their cultural parameters, not agreeing with the teachings of the parents.

Keyword: Guarani. Protagonism. Ñande reko. Jesuits. Leaderships

\section{Introdução}

Precedente à chegada dos espanhóis e dos portugueses, o continente sul-americano já estava ocupado, há milhares de anos, por outros grupos humanos. Os territórios do atual Estado do Rio Grande do Sul eram divididos entre distintas etnias, tais como: Guarani, Kaingang, Xokleng, Charrua e Minuano. O presente estudo tem como foco a etnia Guarani, pertencente ao Tronco Linguístico Tupi e à Família Linguística ${ }^{5}$ dos Tupi-Guarani (URBAN, 1992).

Desde o século XX, há discussões entre arqueólogos e linguistas, em torno do centro de origem dos grupos Tupi; contudo, ainda não houve consenso em relação ao local da dispersão. Neste estudo, optamos pela hipótese defendida por Brochado (1989) e Noelli (1993), que situam em territórios entre o rio Madeira e o rio Amazonas, o local de origem do Tronco Linguístico Tupi.

\footnotetext{
${ }^{5}$ A Família Linguística Tupi-Guarani, além dos Guarani, engloba outras etnias, tais como, os Tupinambá, Asuriní, Xetá, Wayampi, entre outros.
} 
Segundo Brochado (1989), os antepassados dos Guarani, por pressão demográfica, teriam sido forçados a iniciar suas movimentações da Amazônia Central para as proximidades dos rios Madeira, Guaporé e Xingu, onde teria ocorrido a separação dos ProtoGuarani e dos Proto-Tupinambá. Desta separação, teria resultado a movimentação dos Guarani para os territórios das bacias hidrográficas dos rios Paraná, Paraguai e Uruguai.

A expansão Guarani ocorreu de modo lento e gradual. Segundo Noelli (1993), esta dispersão gradativa resultou do manejo agroflorestal ${ }^{6}$. No entender de Rogge (2004), os Guarani ocupavam os territórios do atual Estado do Rio Grande do Sul desde o início da Era Cristã, expandindo-se por este espaço a partir de três etapas: na primeira, teriam se estabelecido próximos aos rios de maior porte, como o Ibicuí, Uruguai e o Igaí (Jacuí). Na segunda etapa, teriam se situado à margem esquerda do rio Igaí, territórios das matas da Serra do Sudeste, chegando às proximidades da Lagoa dos Patos. Por fim, na terceira etapa, os Guarani, por volta dos séculos XIV e XV, expandiram-se para áreas próximas aos vales dos rios Iequi (Pardo), Tebiquari (Taquari), Caii (Caí), onde dois séculos depois entrariam em contato com os europeus.

No século XVII, a Coroa Hispânica deu início à penetração e à ocupação dos territórios do atual estado do Rio Grande do Sul, a partir de um acordo estabelecido com a Companhia de Jesus, no ano de 1607, fundando a Província Jesuítica do Paraguay. Os jesuítas atuariam nos territórios da América Meridional a partir de cinco frentes missionárias: o Guayrá7, Itatim $^{8}$, Paraguay $^{9}$, Uruguay $^{10}$ e Tape ${ }^{11}$ (BECKER, 1992).

Conforme Chamorro (1999), o acordo entre a Companhia de Jesus e a Coroa Hispânica foi uma estratégia adotada para conter as revoltas indígenas contra os espanhóis, principalmente, devido aos trabalhos nas encomiendas. Desta forma, a evangelização foi a estratégia encontrada naquele momento. Além disso, para Gruzinski (2001), a religião foi um dos principais mecanismos utilizados pelos espanhóis para transferir imaginários e instituições europeias para a América. A formação das reduções demonstra a adoção da religião como uma destas estratégias para inserir os indígenas no sistema colonial, pois, nestes espaços missionais, os indígenas aprendiam o modo de vida dos europeus.

\footnotetext{
${ }^{6}$ Tratando-se do manejo florestal temos "[...] que o ritmo da dispersão colonizadora era lento, na dependência do desenvolvimento do manejo agroflorestal, pois a maioria das espécies vegetais só podia ser aproveitada a longo prazo, devido à sua fenologia. Muitas das plantas úteis, cultivadas em grandes extensões, como os palmeirais, os jabuticabais, as madeiras, etc demoravam anos para serem desfrutados como alimento e matéria prima" (NOELLI, 1993, p. 5).

${ }^{7}$ A Frente Missionária do Guayrá abrange os territórios que atualmente formam o Estado do Paraná (BECKER, 1992).

${ }^{8}$ A Frente Missionária do Itatim estaria localizada nos territórios do Pantanal, atualmente o Estado de Mato Grosso do Sul (BECKER, 1992).

${ }^{9}$ Conforme Becker (1992), os territórios que configuram a Frente Missionária do Paraguay abrangem terras da margem oriental do rio Paraguay e a margem ocidental do rio Paraná.

${ }^{10}$ Conforme Becker (1992), em termos de abrangência territorial, a Frente Missionária do Uruguay era a maior, ocupando porções dos territórios de Corriente e Misiones na Argentina e parte do território do Rio Grande do Sul, mais especificamente entre os rios Ibicuí, Piratini e Ijuí.

${ }^{11}$ A Frente Missionária do Tape estava situada nos territórios das bacias hidrográficas dos rios Ibicuí, Jacuí e Pardo (BECKER, 1992).
} 
No século XVII, a Companhia de Jesus adentrou áreas do atual estado do Rio Grande do Sul, em territórios das bacias hidrográficas dos rios Igaí (Jacuí) e Iequí (Pardo), onde, por meio de negociações e alianças com parcialidades Guarani, fundaram cinco reduções (BECKER, 1992). À margem esquerda do rio Igaí, foram estabelecidas quatro reduções jesuíticas: Santa Ana (1633), San Joaquín (1633), Jesus Maria (1633) e San Cristóbal (1634); na nascente deste rio, foi estabelecida a redução de Santa Teresa (1633).

Nestes territórios, os missionários tinham o objetivo de implantar o projeto colonial financiado pela Coroa Hispânica, cujo principal intuito consistia em cristianizar e "civilizar" os indígenas, tidos como "selvagens". Uma vez reduzidos em determinados espaços, os jesuítas insistiam que os Guarani deixassem de realizar algumas das práticas culturais do ñande reko Guarani (o modo de ser), como a poligamia, a nudez e a prática da antropofagia, por exemplo.

Apesar de algumas parcialidades Guarani terem estabelecido alianças com a Companhia de Jesus, a Carta Ânua de 1635 apresenta situações em que os indígenas reduzidos não deixaram de realizar suas práticas culturais, mesmo sob o olhar condenatório dos padres. Há também informações de que diversas parcialidades Guarani não aceitaram realizar alianças com a Companhia de Jesus, condenando os ensinamentos dos jesuítas, que eram contrários aos ensinamentos do ñande reko. Frente ao exposto, o fio condutor do estudo são as parcialidades Guarani que não se instalaram nas reduções e declararam guerra aos missionários. A pesquisa, como abordagem analítica, enquadra-se na Nova História Indígena, tendo como base, por exemplo, os estudos de Manuela Carneiro da Cunha, "História dos Índios do Brasil" (CUNHA, 1998); de John Manuel Monteiro, "Negros da Terra: índios e bandeirantes nas origens de São Paulo" (MONTEIRO, 1994); e de Maria Regina Celestino de Almeida, "Os índios na História do Brasil" (ALMEIDA, 2010), com o intuito de analisar historicidades Guarani.

O objetivo do estudo é analisar a atuação de lideranças, tais como, Tayubai e Apyçaire, que declararam guerra aos padres em nome do nãnde reko Guarani, em territórios dos rios Iequí e Caií, no ano de 1635, a fim de demonstrar a ocorrência de diversas situações de conflitos entre os ensinamentos dos padres e a lógica cultural das parcialidades Guarani. $\mathrm{O}$ presente estudo se justifica tendo em vista a necessidade de analisar o contexto das primeiras missões a partir da perspectiva Guarani, elevando estas parcialidades à posição de protagonistas, embora haja poucas informações sobre quem eram estes sujeitos indígenas. Em virtude disso, a estratégia adotada para analisar as atuações e decisões Guarani buscou focar nas lideranças, pois os padres referiam-se principalmente a elas nas documentações existentes.

A pesquisa é de cunho qualitativo e descritivo, fundamentada na abordagem etnohistórica. A etno-história caracteriza-se por ser um método interdisciplinar, que possibilita o diálogo entre a história, a antropologia, a arqueologia, a linguística, além de outras áreas de 
conhecimento, para a "reconstrução" das historicidades étnicas (CAVALCANTE, 2011). Como o foco da presente investigação são os Guarani do século XVII, especificamente no período de 1633 a 1637, as fontes disponíveis são as produzidas pelos colonizadores, neste caso, os jesuítas. Portanto, recorrendo à hermenêutica e a informações contidas nas entrelinhas da documentação, buscamos "encontrar" pistas sobre a atuação dos indígenas como sujeitos. Segundo Laroque et al. (2015), a etno-história caracteriza-se por ser um método de análise que permite que a História, em conjunto com as demais disciplinas, relativize informações sobre situações de contatos entre colonizadores e sociedades indígenas, tornando-os sujeitos de suas ações.

Vale salientar que, embora a etno-história como metodologia de análise permita o diálogo com a arqueologia, a biologia, a linguística, entre outras disciplinas, conforme os autores mencionados, no caso deste estudo, utilizou-se basicamente fonte documental e bibliografias. Como fonte documental, utilizou-se a Carta Ânua de 1635, referente à Província do Tape, compilada por Jaime Cortesão, na obra, "Manuscritos da Coleção de Angelis: Jesuítas e Bandeirantes no Tape (1615-1641)”, (CARTA..., 1969), tendo em vista a identificação de historicidades das parcialidades Guarani, que viviam em áreas das bacias hidrográficas dos rios Iequí (Pardo) e Caii (Caí), as quais são analisadas tomando por base aportes teóricos sobre etnicidade, cultura e cosmologia, de autores como Barth (2000), Brandão (1986), Castro (2002), Pompa (2001) e Sahlins (1990).

Em relação à Carta Ânua ${ }^{12}$ em questão, bem como as demais, chama atenção que, mesmo após três séculos da sua escrita, continuam sendo estudadas pelos pesquisadores, a fim de compreender encontros e desencontros entre indígenas e jesuítas. Não há dúvidas de que esta documentação é rica em informações. Contudo, os jesuítas, ao escreverem, destacavam os pontos que lhes interessavam, pois a intenção deles não era tratar dos índios, mas abordar como o projeto de catequização estava progredindo. Sendo assim, é preciso uma análise crítica de tais fontes. Deste modo, a etno-história nos parece uma abordagem pertinente para análise dos dados pesquisados.

Revitalizar a história dos Guarani, muitas vezes "minimizados" como sujeitos e protagonistas pela historiografia, não é tarefa fácil, já que a Carta Ânua de 1635, utilizada na presente pesquisa, fornece dados limitados. Por isso, a opção por tratar das lideranças indígenas, já que elas aparecem com mais frequência nos escritos dos padres.

\footnotetext{
${ }^{12}$ Cartas Ânuas são relatórios anuais produzidos pelos jesuítas para enviar aos seus superiores em Roma, cuja intenção consistia em informar sobre a situação do projeto missionário, constituindo-se por ser uma comunicação regular entre os jesuítas e o padre geral da Companhia (MAEDER, 1984).
} 


\section{O ñande reko Guarani}

"Ñande reko" é a denominação dada ao "modo de ser" dos Guarani, englobando questões culturais, sociais, territoriais, econômicas e cosmológicas. Há indicativos de que esta lógica cultural Guarani, o ñande reko, era transmitida através da educação, por meio de estruturas prescritivas no decorrer das gerações, dos mais velhos aos mais jovens, com o objetivo de compreender o mundo onde viviam e os significados da cultura Guarani. O contato com os jesuítas gerou desencontros culturais, pois os ensinamentos dos mais velhos, como a poligamia, a nudez, a lógica cosmológica, entre outros, passaram a ser combatidos pelos padres, acarretando situações de combate contra os ensinamentos cristãos.

Com base no ñande reko, os Guarani classificavam seus espaços de domínio em três categorias territoriais, baseadas em laços de parentesco e de reciprocidade: os Guará, Tekohá e Teîi (NOELLI, 1993). Soares (1997) apresenta o Guarán ${ }^{13}$ como uma área territorial que mantinha a unidade e a identidade sociocultural regional. Neste espaço, ocorriam as relações sociopolíticas, fundamentadas na solidariedade de condutas. O Guará era comandado por uma liderança geral de grande prestígio político e espiritual. No espaço do Guará, os habitantes podiam utilizar o território, praticar a agricultura, a caça e a pesca, por ser uma área de trocas e de reciprocidade entre as famílias.

Os Guará eram subdivididos em vários Tekohá. "Tekohá é a aglomeração aldeã. A coexistência ordenada de multilinhagens num só lugar" (SUSNIK apud NOELLI, 1993, p. 249). O Tekohá formava uma rede de parentesco entre famílias extensas e povoados, onde ocorriam as relações econômicas e sociais (SOARES, 1997). Havia vários Tekohá num Guará. Esta categoria era subdividida em três espaços essenciais para os Guarani reproduzirem o ñande reko: aldeia, roça e mata (NOELLI, 1993). Os Tekohá eram delimitados por acidentes geográficos, como rios, colinas e arroios, que eram de uso exclusivo do grupo local.

Já os Tekohá eram formados pelos Teiî̀ ${ }^{14}$, ou seja, famílias extensas, cuja representação da macrofamília era patrilinear (NOELLI, 1993). Cada Teî̂ era formado por até 60 famílias nucleares, com mais ou menos seis pessoas. O Teî̀ representa as relações de parentesco mais estreitas, que mais se busca afirmar e repetir, por meio de casamentos e alianças (SOARES, 1997).

Os Teî̀ eram formados por pessoas ligadas por laços sanguíneos ou por alianças em torno de uma pessoa com prestígio (SOARES, 1997). “[...] Uma das características do ñande reko, modo de ser Guarani, é a existência de um ancestral mítico comum às linhagens [...]

\footnotetext{
${ }^{13}$ A concepção de Guará foi traduzida por Montoya (1639) como região, pátria, parcialidade.

${ }^{14}$ Segundo Montoya (1639, p. 376), Teiî significa “[...] manada, companhia, parcialidade, genealogia, muchos".
} 
Neste caso, todos os ancestrais são importantes como fundadores de casas" (SUSNIK apud SOARES, 1997, p. 22).

Na sociedade Guarani, após serem realizados os matrimônios, geralmente o noivo se mudava para a casa dos sogros, mas, conforme o prestígio, ele levava a esposa para a casa dos seus pais (SOARES, 1997). No entender dos Guarani, as mulheres tinham importância socioeconômica, uma vez que elas faziam o serviço da roça e eram responsáveis pela reprodução. Deste modo, as mulheres serviam para formar alianças ou o que ficou conhecido no período colonial como cuñadazgo (SOARES, 1997). "Desta forma, ser tovajácunhado compreende a obrigação de reciprocar os bens recebidos, seja uma irmã, prima ou sobrinha, dentro do círculo de parentesco, ou uma escrava raptada, fora do teýy e até mesmo do grupo étnico" (SOARES, 1997, p. 26, grifos do autor).

A partir deste cenário, é possível perceber que os matrimônios tinham significativa relevância dentro do ñande reko Guarani, pois esses laços de parentesco formavam as alianças e demonstravam o prestígio da liderança. Esta prática de alianças através dos casamentos é base fundamental na cultura Guarani, algo que os padres não compreendiam e não aceitavam, pois o cristianismo é contrário à poligamia. Corrobora para a questão o relato de Montoya (1985, p. 37) sobre o espanto dos padres ao encontrarem caciques com quinze a trinta mulheres: "[...] conocimos algunos destos que tenian 15. 20. y 30. mugeres, las del hermano muerto toma a vezes el hermano vivo, y esto no muy comunmente [...]".

Conforme Soares (1997), essas alianças por meio do parentesco, bem como, essas relações políticas contribuíram para a manutenção das relações constantes dos indígenas Guarani entre as diversas aldeias, isto é, manteve-se o ethos Guarani por meio dos seus discursos, práticas, rituais e guerras. Entretanto, para os integrantes das reduções, estas alianças parentais entre as famílias, reduzidas ou não, tornam-se motivos de conflitos entre os ensinamentos cristãos e o ñande reko.

No que tange aos Tuvichá (caciques) Guarani, sabemos que havia um respeito muito grande por eles, pois tais lideranças tinham o papel de tomar as decisões em momentos de dificuldades. Mesmo que não detivessem poderes supremos como os líderes possuíam nas sociedades não-índias, em momentos de dificuldades, esperava-se que o Tuvichá tomasse a frente. A manutenção do ñande reko é um dos motivos de as lideranças Guarani estabelecerem relações de guerra ou alianças com os bandeirantes e jesuítas no século XVII, como é o caso dos eventos tratados a seguir, que ocorreram em territórios das bacias hidrográficas dos rios Iequí (Pardo) e Caii (Caí).

Em relação à questão cultural do ñande reko Guarani, destaca-se que a cultura não é uma estrutura estática, mas, sim, dinâmica; todavia, entende-se que a cultura fundamenta ações e interpretações das situações vivenciadas. A cultura é reproduzida a partir da ação, ou seja, 
conforme o contexto histórico, contatos com o outro e até mesmo conforme a subjetividade de cada um dos envolvidos (SAHLINS, 1990).

No ñande reko Guarani, segundo nosso ponto de vista, predomina uma estrutura prescritiva, na qual, conforme Sahlins (1990) é mantida a reprodução social muito mais por permanência do que por transformações. Contudo, as vivências e contatos dos Guarani com outros grupos indígenas, com os colonizadores ibéricos e também com as próprias parcialidades que se dividiam, possivelmente acarretaram atualizações na base cultural no ñande reko. Reforça a hipótese o fato de as transformações/ressignificações culturais ocorrerem ao longo da história, o que acreditamos também ter ocorrido com os Guarani em estudo, pois, mesmo as sociedades tradicionais jamais viveram isoladas, como muitos antropólogos acreditavam (SAHLINS, 1990).

Em vista disto, entendemos que as parcialidades Guarani que atuaram nas reduções não abandonaram o ñande reko Guarani, mas o ressignificaram, à semelhança do que fizeram as parcialidades Guarani, que se declararam inimigas dos padres. Embora não seja o foco deste trabalho, não ignoramos que os jesuítas também foram influenciados pelas lógicas culturais dos Guarani; portanto, também precisaram ressignificar seu projeto original. Contudo, nestes primeiros contatos relatados na Carta Ânua de 1635, evidencia-se que os Guarani agiram de modos distintos em relação à presença dos padres, ou seja, algumas parcialidades aceitaram contrair alianças; já outras, possivelmente mais influenciadas pelas lideranças espirituais indígenas, os rejeitaram terminantemente e recorreram à estratégia da guerra.

\section{Rebeldia espiritual: a luta das lideranças espirituais para manter o ñande reko Guarani}

Conforme abordado, nem sempre os indígenas Guarani aceitavam aliar-se aos integrantes do projeto colonial jesuítico, dando margem a situações de conflito e à deflagração de guerras entre os padres, os indígenas missionados e os grupos não reduzidos, sendo as desavenças culturais a justificativa para os desentendimentos. Na maioria dos conflitos entre Guarani e jesuítas, as lideranças espirituais, os Paye, comandavam as incursões guerreiras, manifestando não só o descontentamento com os ensinamentos cristãos, mas, também, a insatisfação por serem depreciados pelos Guarani reduzidos, o que indica uma disputa de poder entre estas lideranças espirituais e os padres, a qual se expunha a partir dos conflitos entre o ñande reko e o cristianismo. 
O termo "feiticeiro" ou "hechizero" é utilizado pelos jesuítas para se referirem aos Paye, considerados pelos padres como homens pagãos e hereges. Contudo, para as sociedades indígenas, os Paye tinham o poder de comunicar-se com os espíritos e o poder de cura, mas, para os padres, esses poderes não passavam de práticas pagãs e demoníacas (ALVIM, 2004).

Essa concepção dos padres deve-se ao contexto vivenciado na Europa, ressaltando que a Companhia de Jesus é oriunda de um período de Reformas e de caça às bruxas através da Inquisição. Conforme descreve Ginzburg (2012), no imaginário europeu, as bruxas e feiticeiros costumavam reunir-se em locais solitários, em campos ou montanhas.

\begin{abstract}
Os que vinham pela primeira vez deviam renunciar à fé cristã, profanar sacramentos e render homenagem ao diabo, presente sob a forma humana ou (mais frequentemente) como animal ou semianimal. Seguiam-se banquetes, danças, orgias sexuais. Antes de voltar para casa, bruxas e feiticeiros recebiam unguentos maléficos, produzidos com gordura de criança e outros ingredientes (GINZBURG, 2012, p. 9).
\end{abstract}

Deste modo, parece-nos claro que os jesuítas projetaram sobre as lideranças espirituais indígenas tal imaginário, já que os Paye costumavam viver de modo isolado dos grupos Guarani, em contato com a natureza e os espíritos. Conforme Castro (2002, p. 468), os xamãs eram homens capazes de ultrapassar as barreiras humanas e atingir um nível de subjetividade não-humana. "Sendo capazes de ver os não-humanos como estes se vêem (como humanos), os xamãs ocupam o papel de interlocutores ativos no diálogo cósmico". Já, segundo a interpretação dos jesuítas, o demônio manifestava-se através dos Paye, com o objetivo de impedir a cristianização (POMPA, 2001).

A análise da Carta Ânua de 1635 possibilitou identificar dois casos em que parcialidades indígenas lideradas pelos Paye Guarani declararam guerra contra os padres, provocando conflitos com os jesuítas e com os Guarani reduzidos. A primeira situação ocorreu em 1635, quando o padre Cristóval de Mendonza ${ }^{15}$ adentrou os territórios próximos aos rios Tebiquari (Taquari), Mboapari (Antas) e Caii (Caí), conforme mapa (figura 1), com o intuito de sondar a possibilidade de catequizar os grupos indígenas localizados nesta área.

\footnotetext{
${ }^{15}$ Destacamos que, ao longo da documentação analisada, os nomes próprios de sujeitos, rios, locais etc, são escritos de distintas maneiras. O nome do padre Cristóval Mendonza encontra-se descrito como Mendonza e Mendonça, deste modo, decidimos pela utilização de Mendonza para nos referirmos a ele. Entretanto, nos trechos que fazemos citação direta, utilizaremos a ortografia tal como está descrita.
} 
Partió el Padre a ver la disposicion desta tierra del Igai acompanado, segun dize el Padre Pedro Mola, de la gente q pareció sufficiente para su seguridad, y aviendo passado el Igai, y el Ibia llegó al Caagua, donde la gente Le recibió mui bien (CARTA..., 1969, p. 101).

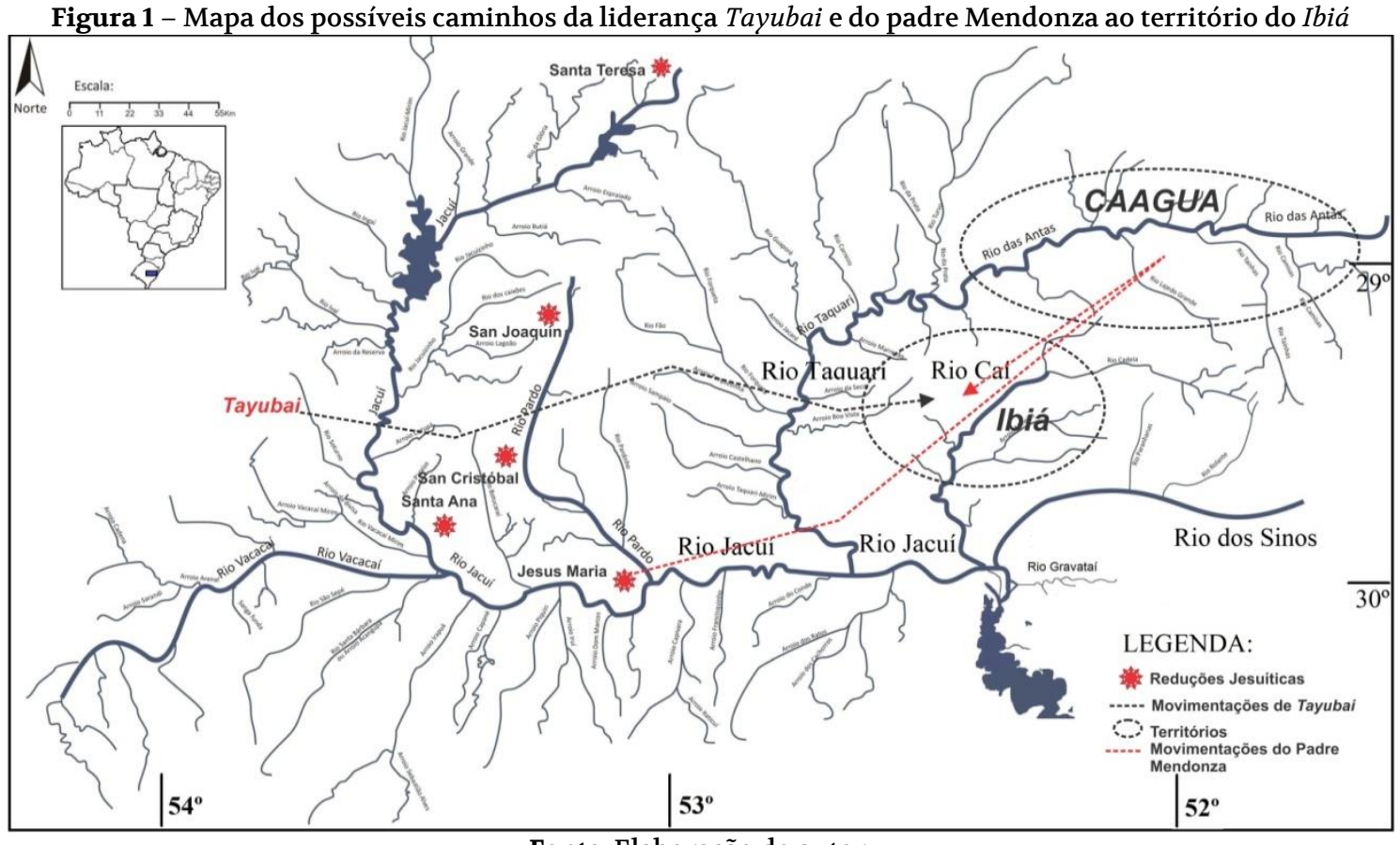

Fonte: Elaboração do autor.

As parcialidades estabelecidas em tais territórios teriam aceitado aliar-se aos jesuítas e se dirigirem às reduções com ele. Mesmo assim, o padre estava preocupado, haja vista que as reduções da serra não estavam conseguindo autossustentar-se, visto que a colheita do ano fora ruim, "[...] les dixo q no era aun tiempo, q perecerian por aca de hambre, y q asi se estubiessen por entonces em sus tierras [...]" (CARTA..., 1969, p. 101).

Após o encontro com os indígenas do $\mathrm{Caagua}^{16}$, o padre Cristóval de Mendonza iniciou o caminho de volta para a redução de Jesus Maria, de onde havia partido para sua incursão aos territórios do Caagua (figura 1). Mais especificamente em territórios do Ibiál7, estava estabelecido um guerreiro Guarani, denominado de Tayubai, que já era um "velho conhecido" do padre Cristóval de Mendonza.

\footnotetext{
${ }^{16}$ Tratava-se de uma "[...] região que cortava a província do Ibiaçá, ligando ao Sul e Oeste com a região de Ibia, ocupava toda a extensão da Serra Geral, que se estende entre o litoral e o vale do Taquari [...]" (PORTO, 1954, p. 50).

${ }^{17} \mathrm{O}$ termo "Ibiá", dependendo do contexto utilizado, pode ter significado variado. Isto é, "Travessia do caminho do rio", "caminho difícil" ou mesmo "terras altas" e "planalto". Sabe-se que "[...] foi o primeiro nome dado à região que hoje tem como sua maior representante Montenegro" (PROENÇA, 2014, p. 96-97)
} 
En el Ibia avia entre otros, un indio huido de S. Miguel, llamado Tayubai, a quien el miesmo Padre Xptoval de Mendonça ahora un ano avia procurado corrigir y el no pudiendo sufrirlo. se huyó de nuestras reduciones"(CARTA..., 1969, p. 101-102).

Tayubai, uma liderança espiritual Guarani contrária aos ensinamentos do cristianismo, tentou persuadir as parcialidades presentes em San Miguel a desfazer a aliança com os jesuítas (MONTOYA, 1985). Entretanto, estes indígenas não teriam acreditado em seu discurso e o capturaram para que o padre Cristóval de Mendonza o convencesse a aceitar o Evangelho. Por discordar das palavras do missionário, Tayubai escapou de San Miguel e estabeleceu-se em territórios do Ibiá, onde encontrou Mendonza, em 1635, conforme mapa (figura 1), (CARTA..., 1969; MONTOYA, 1985).

Ao avistar a presença de Mendonza nestes territórios, Tayubai teria se reunido com as parcialidades Guarani lideradas por Paye e Tuvichá (caciques) para avaliarem a questão. Segundo Montoya [1639], 1985, Tayubai discursou aos indígenas reunidos a fim de persuadilos a não aceitar a doutrina proposta pelos cristãos, pois condenavam o modo de viver dos Guarani, por exemplo, não permitindo que os homens tivessem mais de uma esposa.

[...] ayudandose de un hechizero llamado Tayabaiba, y otros Caciques llamados Guinpi, Ñanduai, Tabeçaca, Yapepoyaca, y otros muchos conbocó un gran numero de gente de toda aquella tierra y diziendoles mucho mal del Padre les persuadió q le matassen y le armaron la zelada para la buelta en Ibia (CARTA..., 1969, p. 102).

Padre Ximenez ressalta ainda que os territórios do Ibiá eram de difícil locomoção e com áreas propícias para a realização de emboscadas: "[...] tierra, segun dizen, mui a proposito para ello por los grandes riscos y penascos y passos forçosos del camino" (CARTA..., 1969, p. 102). Ao saber que Mendonza estava retornando à redução de Jesus Maria, as parcialidades Guarani referidas enviaram ao encontro do padre três guerreiros, com a alegação de que seria bem-vindo no local. O restante dos guerreiros aliados a Tayubai, espreitados na mata, esperaram que o missionário chegasse e se estabelecesse num local para passar a noite. Porém, ao serem descobertos por um dos Guarani que acompanhavam o padre, decidiram pelo ataque imediato.

Los q le acompanaban se defendieron, y mataron dos o três de los enemigos, y estos a un alcalde infiel, q acompanaba al $\mathrm{P} .^{\circ}$ sintió mucho 
su muerte y por q no sucediesse otro tanto con otro, trato de baptizar los infieles y pidió agua para hazerlo, mas no dandole lugar la multidud de los enemigos q los iban cercando, dixo que se huyessen todos los infieles y $\mathrm{q}$ los Xpnos hiziessen rostro, y el mismo $\mathrm{P}^{\circ}$ começo a escamuraçar com el Cavallo deteniendo los enemigos para dar lugar a $\mathrm{q}$ sus hijos se salvassen [...] (CARTA..., 1969, p. 102).

O padre Ximenez descreve na Carta que o padre Mendonza, mesmo frente ao conflito guerreiro, teria tentado proteger seus companheiros, colocando-se entre eles e as flechas dos inimigos. Nesse sentido, há a informação de que "[...] ni los enemigos le dieron lugar porq le cercaron con grande impetun, en este tiempo dixo otra vez a los q le acompanaban, q se huyessen q poco importaba q el murriesse [...]" (CARTA..., 1969, p. 102).

A parcialidade Guarani, liderada por Tayubai, atacou o padre com flechas e pauladas, de modo que este caiu desfalecido. Imaginando que Mendonza havia falecido, os guerreiros decidiram queimar o corpo, mas, surpreendidos por um temporal, decidiram deixar o corpo no local com o plano de regressar no dia seguinte para realizar a tarefa. Ao retornarem pela manhã, surpreenderam-se ao encontrar o padre ainda moribundo. Deste modo, "[...] despues le procuraron quemar, mas no pudieron salir con su intento, ora sea porq la lena estaba mojaba, ora porq Nuestro Senhor no lo permitió [...]" (CARTA..., 1969, p. 103).

Contudo, chegada a notícia da morte do padre Mendonza às reduções do Iequí (Pardo), os Guarani missionados reuniram cerca de $\mathbf{1 . 6 0 0}$ homens para resgatar o corpo. Conforme Ximenez, a ordem dada ao grupo era de que apenas trouxessem o corpo e não se envolvessem em conflitos com os indígenas "infiéis". Entretanto, a luta foi inevitável, visto que o grupo de Tayubai atacou os Guarani que faziam parte das reduções, "[...] mas los bellacos no dieron lugar a esso porq dios por ventura los quiso castigar [...]" (CARTA..., 1969, p. 103).

Na Carta de 1635 e na obra a "Conquista Espiritual" de Montoya (1985), percebe-se como o discurso é reproduzido para acusar e condenar os indígenas liderados por Tayubai que atacaram Mendonza. Ou seja, a cada palavra utilizada na narrativa de Ximenez (1635) e de Montoya (1985), o intuito é claro: transformar Mendonza num mártir, numa vítima de grupos selvagens e infiéis. Assim, percebe-se o que Baptista (2004) chama de "modelo de discurso", encontrado em várias cartas ânuas deste período, isto é, uma lógica fundamentada na premissa do "pecado-castigo-conversão".

$\mathrm{Na}$ investida guerreira a Mendonza e a seus companheiros, o "castigo divino" pelo pecado cometido é evidenciado em vários momentos: na chuva que impede que o corpo do padre seja queimado na noite do conflito, na lenha molhada que não permite a queima do 
corpo no segundo dia e, finalmente, o castigo final, que chega com o confronto provocado por eles mesmos contra os Guarani reduzidos. "[...] antes q los Nuestros llegassen donde el cuerpo estaba les salieron al encuentro flechandoles. intentaron segun dizen los nuestros hablarles, mas no dieron lugar, antes mostrando los pedaços de la sotana del Padre [...]" (CARTA..., 1969, p. 103).

A partir do conflito guerreiro liderado por Tayubai, os Guarani das reduções protagonizaram vingança, matando alguns e aprisionando outros. Somente no dia seguinte ao confronto, eles chegaram ao corpo de Mendonza. Um novo confronto ocorreu entre ambos os grupos, "[...] mas fueron otra vez puestos en huida con muerte de muchos, y entre ellos casi todos los q immediatamente pusieron las manos en el Padre [...]" (CARTA..., 1969, p. 103).

Tayubai, apontado como o principal responsável desta tragédia do Ibiá, foi aprisionado por Guaimicaru - Capitão da redução de San Miguel de onde aquele teria saído fugido (figura 1) - o levou até onde estava o corpo do missionário. Ao chegar ao local, Guaimicaru, como forma de vingança, matou Tayubai e, com o auxílio dos demais indígenas do grupo, carregaram o corpo do padre até a redução de Jesus Maria.

Não é intenção desta análise tomar uma posição em relação a este evento, mas apresentar o fato ocorrido e os significados para cada grupo. Analisando a situação, percebese que as parcialidades indígenas que atacaram o padre Mendonza declararam guerra aos jesuítas porque não desejavam que os integrantes da Companhia de Jesus continuassem a incursionar por seus territórios. A presença de Tayubai no conflito demonstra que os ensinamentos dos padres não eram aceitos por todos os indígenas reduzidos, mas, ao contrário, muitos, ao longo do processo de catequização, desentendiam-se com os ensinamentos e imposições dos missionários sobre o ñande rekõ Guarani e fugiam.

A pessoa é uma construção da sociedade onde vive. Por meio da educação, o coletivo se impõe ao indivíduo, moldando a sua identidade. Assim, podemos concluir que esse sujeito/pessoa é uma expressão da estrutura de símbolos do mundo social onde vive, na medida em que ele carrega aspectos culturais deste grupo, o que lhe foi ensinado ao longo da vida (BRANDÃO, 1986). Com base no que afirma o referido autor, compreendemos que a atitude de Tayubai está baseada no ñande rekõ Guarani, ou seja, ele reage aos ensinamentos dos padres, que são contrários aos saberes recebidos ao longo da vida, como, por exemplo, ter mais que uma esposa.

A documentação é um reflexo de seu contexto e de quem a realiza, de modo que cabe ao pesquisador desvendar mistérios, preencher lacunas e evitar "armadilhas", a que, muitas vezes, uma narrativa documental pode induzir. As cartas ânuas, como refere Baptista (2004), reproduzem um discurso, uma visão de mundo bastante distinta do olhar do indígena, ou seja, elas reproduzem o discurso colonial. 
Deste modo, o leitor sem maiores conhecimentos sobre as culturas indígenas, ao deparar-se com os documentos coloniais, tem dificuldade de desfazer-se de "pré-conceitos", de discursos preconceituosos dos não índios. A vingança realizada por Tayubai e seus companheiros estava fundamentada na luta contra as imposições dos jesuítas sobre o modo de viver dos Guarani, o ñande reko, como, por exemplo, as relações poligâmicas.

Conforme abordado, os homens com maior prestígio no grupo, geralmente, possuiam várias esposas, o que demonstrava que eles mantinham alianças com outros Teii e Tekohá, gerando assim maior poder econômico e bélico (SOARES, 1997). Maior poder econômico, porque, para os Guarani, o cultivo e a coleta das roças eram realizados pelas mulheres; logo, quanto mais esposas o homem tinha, tanto maior seria a produção de alimentos para a família e também para os seus atos de generosidade. No que se refere ao poder bélico, quando ocorria algum conflito, as famílias com as quais os líderes tinham alianças parentais auxiliavam na guerra, seja na defesa ou no ataque.

Resumindo, os casamentos eram a estrutura socioeconômica dos Guarani. Quanto mais esposas, maior, o prestígio das lideranças. Os padres, ao combaterem esta prática cultural dos Guarani a partir da lógica do cristianismo, não apenas desestruturam uma das bases fundamentais do ñande reko, como também geram descontentamentos entre as lideranças, que geralmente eram os que possuíam mais esposas. Além disso, os padres tentavam tomar o lugar das lideranças espirituais dentro da organização sociopolítica indígena. Sendo assim, quase tudo o que estas lideranças pregavam era condenado pelos padres. $O$ fato de Tayubai ter entrado em discordância com Mendonza, ainda em sua redução, ilustra, em nosso entendimento, esta disputa de poder com o missionário, principalmente, quando Tayubai discursa contra os ensinamentos cristãos.

No que se refere à reunião de Tayubai com outras lideranças dos territórios do Ibiá, pode-se deduzir que estes territórios formavam mais do que um Tekohá, talvez constituíssem um Guará. Considerando que na Carta Ânua de 1635, Ximenez relatou que se reuniram diversos caciques (Tuvichá) com Tayubai, tais como Guinpi, Nanduai, Tabeçaca, Yapepoyaca, entre outros que poderiam ser as lideranças destes Tekohá.

O segundo evento a ser analisado, ocorreu na redução de Jesus Maria e envolve a participação dos Guarani presentes nas reduções de San Cristóbal e San Joaquin. O padre Taño, em seu relato aos superiores, inicia descrevendo a situação em que se encontravam as reduções da Serra. O missionário destaca que havia falta de mantimentos, roupas e armamentos e que tudo havia piorado após a morte do padre Mendonza (CARTA..., 1969). O missionário descreve que muitas casas dos indígenas da redução de Jesus Maria estavam se deteriorando e que algumas estavam abandonadas. "[...] preguntando un dia a los yndios $q$ donde estavan y $\mathrm{q}$ era la causa de perderse sus casas me dixeron $\mathrm{q}$ unos yeroquiharas $\mathrm{q}$ andaban por los tetaminis los enganaban diciendo q este pueblo se avia de destruir [...]" (CARTA..., 1969, p. 106). 
Conforme Taño, estes Yeroquiharas riam dos ensinamentos dos padres, "[...] y deçian q ellos eran dioses y criaban los maisales y comida [...]" (CARTA..., 1969, p. 106). Teriam afirmado ainda que, além de deuses, eram senhores dos fantasmas das montanhas dos Itaquiçeyas e Ybitipos $^{18}$. Ademais, destacaram que os tigres faziam o que eles desejassem, matando quem eles escolhessem. "[...] y q los Primeros q avian de Pereçer avian de ser los baqueros y ybirapondaras y los q se haçian Xpianos y q los q trabajavan en el pueblo se les avia de perder las comidas [...]" (CARTA..., 1969, p. 106).

Os informantes relataram ao padre Taño que, após esses discursos dos Yeroquiharas, os Guarani que estavam na redução de Jesus Maria iniciaram os trabalhos nas plantações; entretanto, surgiram em suas roças ratões que causaram grandes danos. Os Yeroquiharas afirmaram aos Guarani reduzidos que eles eram os mandantes do ataque as suas roças. Imediatamente, muitos indígenas, principalmente os vaqueiros e os carpinteiros, abandonaram a redução ou deixaram de cultivar suas roças.

Conforme abordado, os Paye possuíam o poder de comunicar-se com os animais, pois afirmavam que os "tigres" e os ratões faziam o que eles ordenassem. Conforme o estudo de Castro (2002) acerca das lideranças espirituais, os Paye agiam como se fossem diplomatas das relações interespécies, defrontando-se com distintas categorias socionaturais. Assim, o missionário soube da presença deste Paye nas redondezas e que este afirmava "[...] q el avia muerto antiguamente y avia buelto a vivir y para esto tomo el nombre de um hechiçero $q$ V.R. fue a coger al ygayriapipe llamado ybapiri" (CARTA..., 1969, p. 107).

Na Carta, o padre Taño destaca que reuniu os Tuvichá e capitães e desmentiu os "bellacos". A partir daí, nos sermões e doutrinas, passaram a dar o "remédio" aos demais indígenas da redução, afirmando que tudo não passara de mentira destas lideranças espirituais (CARTA..., 1969). O padre recomendou ao grupo de Guarani missionados que eles deveriam ir em busca desses "hechizeros", para pôr fim às mentiras e, caso se negassem, ele chamaria os indígenas de outras reduções para realizar o serviço. "[...] y a la mañana les veo venir cargados de flechas y arcos y porras diçiendo q iban por el hechiçero. alabeles el animo. fueron e cogieron três bellacos semejantes en três pueblecillos y el ybapiri se escapo" (CARTA..., 1969, p. 107).

Estes dados permitem tecer algumas considerações, a fim de compreender essa "necessidade" de busca do padre Taño pelo suposto Paye que "ameaçou" os índios reduzidos. Recorrendo ao estudo de Brandão (1986), temos que o "outro", o "diferente" tende a assustarnos e, ao mesmo tempo, ele nos atrai; por isso, o desejo de domá-lo e de explicá-lo. Seguindo esta linha de raciocínio, é inegável que os missionários sentiam necessidade de ir em busca destes "infiéis", o "outro", com o objetivo de demonstrar aos índios reduzidos que eles não deveriam temer as ameaças desses Paye.

\footnotetext{
${ }^{18}$ Por falta de maiores informações não temos a localização desses locais mencionados.
} 
O intuito dos jesuítas era demonstrar aos Guarani reduzidos que essas lideranças espirituais não deveriam ser temidas; assim não haveria motivo para deixar a evangelização. Os missionários sabiam utilizar a palavra para convencer os índios de que era "Deus" quem deveria ser temido. Contudo, nem sempre esses discursos convenciam os Guarani.

Os Paye capturados foram levados à redução de Jesus Maria. Nesse sentido, consta que: "[...] a todos los truxeron los índios bien açotados y manietados y aqui en el pueblo hicieron burla dellos, los muchachos llenaron de todo con q le vinieron a perder el miedo, diçiendo q hiçiesen venir alli los yaguareces y los itaquiçeyas y los ybitipos [...]" (CARTA..., 1969, p. 107).

Neste mesmo período, chegou à redução de Jesus Maria a notícia de que havia outro Paye que estava se deslocando em direção ao pirayubi e a outros povoados das redondezas. $\mathrm{O}$ Capitão Antonio se ofereceu para ir à captura do suposto Paye; entretanto, Antonio descobriu que não era apenas um, mas, sim, “[...] una junta de bellacos comedores de carne humana [...]" (CARTA..., 1969, p. 107). Este grupo de "bellacos" já teria "comido" muitas crianças e índias dos arredores e das reduções de Jesus Maria, San Cristóbal e San Joaquín.

Vale, aqui, um esclarecimento sobre os "comedores de carne humana", pois os Guarani praticavam o ritual antropofágico, assim como outros grupos pertencentes ao tronco linguístico Tupi-Guarani. Castro (2002), ao discorrer sobre o ritual praticado pelos Araweté e os Tupinambá, define o ato como um processo de transmutação de perspectivas: “[...] onde o devorador assume o ponto de vista do devorado, e o devorado, o do devorador: onde o 'eu' se determina como 'outro' pelo ato mesmo de incorporar este outro, que, por sua vez, se torna um 'eu'" (CASTRO, 2002, p. 462). Ainda, segundo o referido autor, o ritual antropofágico é a maneira como os indígenas assumem o ponto de vista do inimigo, isto é, se põem no lugar do outro. Além disso, a quantidade de carne ingerida não tinha importância, mas, sim, a ritualização, a situação em que se enquadram os Guarani em análise.

Com base nos estudos de Castro (2002), problematizamos a narrativa do padre ao afirmar que o grupo de Paye havia devorado crianças e adultos de praticamente todo o povoado. Sabendo que o ato de ingerir carne humana praticado por várias sociedades possui um significado simbólico, sendo as "vítimas" e os "praticantes" geralmente guerreiros renomados, pode-se concluir que o discurso dos padres de que esses indígenas haviam simplesmente "devorado" crianças é demasiadamente simplista.

Na sequência do conflito que se estabeleceu, conforme relato missionário, diversos indígenas situados em povoados próximos a estas reduções e que foram atacados pelas lideranças Chemboabaete, seu filho Yeguacaporu e o irmão de Yguarobi, juntavam-se aos "hechizeros" por medo deles. 
[...] y para mejor disimularse avian echado nueba como yeguacaporu avia muerto y q chemboabaete avia ahogadose en el Rio y q yguarobi venia huyendo de los Portugueses. Por averle cogido sus mugeres, pero decian q todo esto avia sido traça suya para encubrirse y yr enganando la gente [...] (CARTA..., 1969, p. 107).

No rol desses acontecimentos, as lideranças espirituais começaram a agrupar-se no cariroy e partiram em direção ao Pirayubi, onde falaram com "[...] un grande bellaco lunatico o endemoniado q estos llaman apiçayre comedor de carne humana [...]" (CARTA..., 1969, p. 108). O Paye Apiçayre teria outros companheiros "comedores de carne" que se juntaram aos "bellacos".

Com a intenção de enganar as pessoas dos povoados atacados, inicialmente, teria sido enviado o grupo de Yeroquiharas "[...] baptiçadores y enbusteros q yban entreteniendo la gente en los puebleçillos para quando ellos llegasen [...] (CARTA..., 1969, p. 108). Conforme padre Taño, eles chegaram aos territórios do Tayaçuape ${ }^{19}$, ver mapa (figura 2), onde teriam influenciado muitas pessoas, assim como haviam persuadido os Guarani das reduções de Jesus Maria, São Joaquin e San Cristóbal. O Capitão Antonio teria se deslocado em busca deste Paye e no caminho encontrou-se com o Capitão Ariya da redução de San Joaquin. Ariya relatou os últimos acontecimentos, haja vista que Ariya teria se disfarçado e participado de uma dessas festas nas quais os Paye "devoraram" crianças e que diziam que atacariam as reduções (CARTA..., 1969).

Figura 2 - Mapa das possíveis movimentações dos Paye e dos Capitães Antonio e Ariya aos territórios do Tayaçuapé

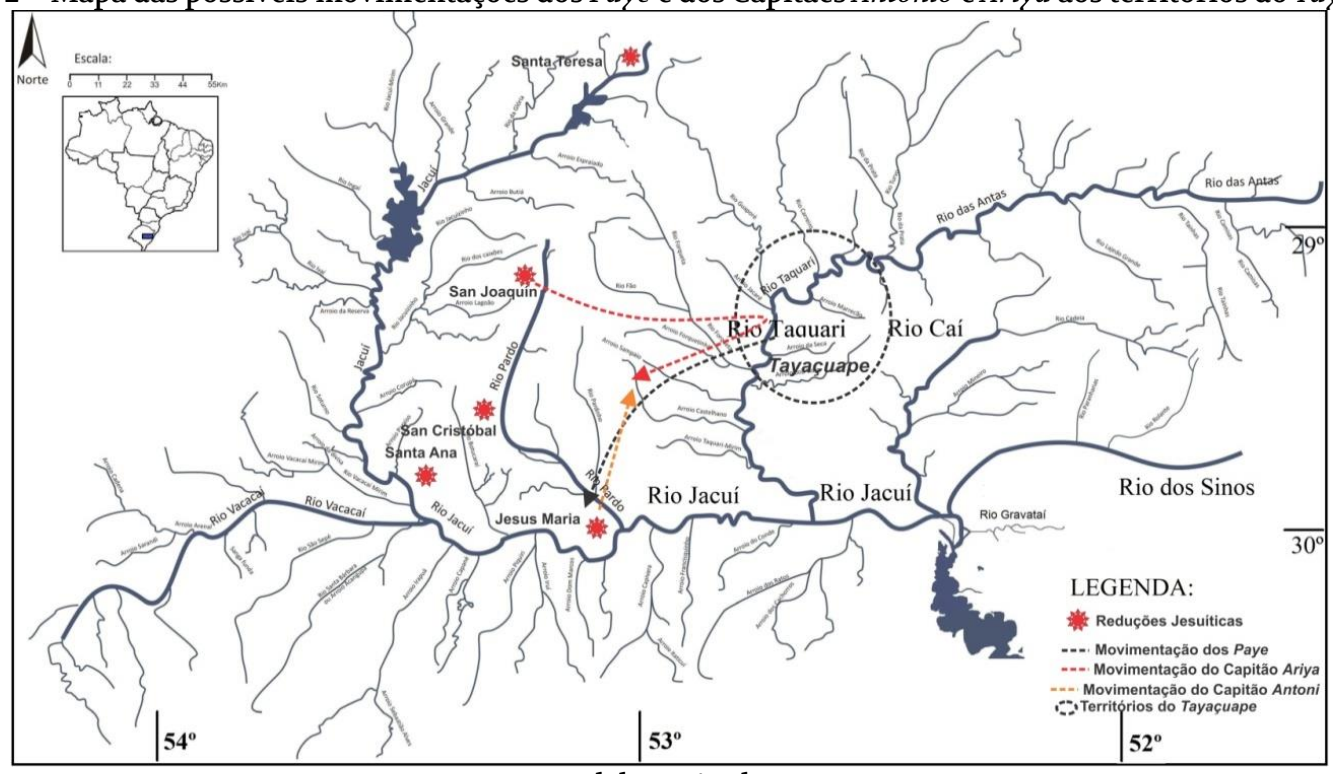

Fonte: Elaboração do autor.

${ }^{19}$ Conforme Weirich (2006) e Relly, Machado e Schneider (2008) Tayaçuape seria os territórios que atualmente configuram-se como o município de Colinas no Vale do Taquari, Rio Grande do Sul. 
Com o intuito de capturar e de desmantelar estas lideranças espirituais, foi reunido um exército com cerca de 1.000 indígenas, enviados das reduções de Jesus Maria, San Cristóbal, San Joaquín e Santa Ana. Um dos grupos que provinha destas reduções, em meio ao percurso até Jesus Maria, havia capturado um dos discípulos de Yeguacaporu: "[...] un hechiçero comedor de carne humana dicipulo de yeguacaporu q le a servido mucho tiempo de cogerle y en laçarle perdiçes [...]" (CARTA..., 1969, p. 109).

O Paye, que fora feito prisioneiro e chegou à redução onde estavam reunidos os indígenas que sairiam à captura do grupo de Yeguacaporu, afirmou que ele era o filho do Sol, portanto, era um deus. Conforme o padre Taño, ele repetia tanto essa afirmação, que tiveram que calar-lhe a boca com algumas pancadas.

[...] los indios viendo esto le començaron a ultraja y a tirar de la guasca en q venia atado y a correr tirando del dando con el en tierra a darlecoçes y a llevarlo arrastrando y a picarle con las flechas q si no voy corriendo lo matan. el pobre desventurado del hechiçero quedo como sin sentido y aunq despues le pregunte algunas cosas no consertava; estaba fuera de si [...] (CARTA..., 1969, p. 109).

O relato evidencia que o padre não aprovou a conduta dos indígenas reduzidos que atacaram o "prisioneiro". Observa-se ainda que o missionário sente necessidade de insistir nessa desaprovação, no relato aos seus superiores, deixando claro que os "selvagens" eram os Guarani, mesmo que fizessem parte da redução. Após retomar a consciência, o Paye aprisionado confirmou ao padre o que os Capitães Ariya e Antonio haviam relatado. O grupo de Paye era realmente liderado pelas renomadas lideranças espirituais Yeguacaporu, Aguarobi e Chemboabete "[...] mus ensignes de los luçitanos [...] (CARTA..., 1969, p. 109, grifo nosso).

Conforme Montoya (1985), "mu" significava "contratantes" ou "pombeiros", eram indígenas que realizavam alianças com os portugueses auxiliando-os na compra e na captura de indígenas. Em troca, recebiam ferramentas, roupas e outros objetos. Os $m u$ incitavam os indígenas a guerrearem e a capturarem os seus inimigos para lhes vendê-los em troca de objetos.

Ademais, estas lideranças espirituais traziam consigo um rapaz vestido com um colete de anta, um grande dançador, que afirmava ser filho de portugueses. De fato, percebe-se pela narrativa que o padre acreditava que o rapaz fosse filho de alguma indígena de Yeguacaporu com algum lusitano (CARTA..., 1969). 
Conforme o padre Taño, os Tuvichá das redondezas é que haviam chamado os Paye, pois não desejavam a presença dos jesuítas em seus territórios, já que não consideravam corretos os seus ensinamentos. Além disso, descobriram, por intermédio de dois índios e uma índia que sobreviveram aos ataques destas lideranças espirituais ao seu pueblo, que:

"[...] q al pareçer tenemos toda la frontera contra nosotros: los Ybianguaras q mataron el Santo Padre Xpval y estos del caatimé y del caamomé y los del tayaçuape Pirayubi y tebiquari y de alli hasta el cariroy les ayudan los de guaybirenda tambien mu de los Portugueses [...]" (CARTA..., 1969, p. 110).

O grupo que saiu em busca das lideranças espirituais Guarani, liderado pelos capitães Antonio, Aryia, Guirarague, Tapayu e Manoe, além do Tuvichá Caaobi, chegou ao rio Yequiyimini. Como havia chovido, alguns conseguiram atravessar enquanto os outros construíam uma ponte para passar; entretanto, aqueles que passaram foram atacados por indígenas enviados pelos Paye. Vale salientar que os índios reduzidos os derrotaram e assim descobriram onde estavam as lideranças espirituais Guarani que comandavam os ataques.

Conforme Baptista (2004), os jesuítas, ao trazer a pastoral do medo para a América e, consequentemente, para as reduções, souberam utilizar muito bem o temor que a natureza podia causar aos indígenas a seu favor. Nesse sentido, atentamos para a forma como o discurso dos jesuítas moldava-se às suas necessidades. Por exemplo, quando ocorriam fenômenos meteorológicos, como tempestades, raios, aumento do nível da água nos rios, a interpretação destes eventos variava conforme as necessidades dos padres naquele contexto, podendo "demonstrar" glória ou ira divina.

No primeiro evento analisado, quando o padre Mendonza estava enfrentando a investida guerreira da parcialidade Guarani liderada por Tayubai, muitos foram os empecilhos causados pela natureza através da "intervenção" divina, no caso, chuva e lenha molhada. Estas supostas intervenções divinas atrapalharam os guerreiros de Tayubai no ataque ao padre, dando tempo para que Mendonza pudesse demonstrar toda a sua fé, quando mesmo moribundo batizou alguns companheiros mortos no ataque e ao sobreviver dois dias sob essa provação divina.

Tratando-se do segundo evento em análise, a situação não é diferente, considerando que o grupo de índios reduzidos segue em direção aos Paye, mas ocorre uma chuva, que elevou as águas do rio e impediu a passagem dos Guarani catequizados. Entretanto, na situação arrolada, em nenhum momento, houve menção a qualquer tipo de interferência divina 
neste fato, já que, no caso em questão, os Guarani não reduzidos estavam sendo "favorecidos pela natureza" e não os índios cristianizados, o que comprova a ideia de que os discursos são moldados conforme as necessidades. É claro que os indígenas, principalmente as lideranças espirituais, também sabiam utilizar esses "discursos" para ludibriar os jesuítas.

O grupo de Paye, ao perceber que estava sendo derrotado, iniciou a fuga; porém, os índios reduzidos conseguiram capturar e matar muitos deles como foi o caso da liderança Paye Guiaba e uma velha Paye, cujo nome não foi relatado. Descobriram que esse grupo de Paye não dispunha do auxílio dos portugueses. Além disso, o famoso Paye Yeguacaporu não teve participação nesses conflitos, pois já havia falecido. O grupo apenas usou a fama de Yeguacaporu como grande liderança espiritual para assustar os índios reduzidos. Já Chemboabate estava vivo; porém, também não teria participado dos conflitos, pois teria se estabelecido em territórios de Cariroy, nas proximidades da redução de Santa Teresa.

A partir dessas narrativas, podemos atentar para algumas questões, como o fato de as lideranças espirituais Guarani que se revoltaram contra as reduções terem sido solicitadas pelos Tuvichá dos povoados próximos às reduções. Essas lideranças não gostavam da presença dos jesuítas em seus territórios, assim como não aprovavam os ensinamentos cristãos, entre eles, as nomeações para postos políticos e as novas hierarquias criadas pelos padres.

Para os Guarani, o posto de Tuvichá, por exemplo, deve ser conquistada a partir de uma série de características, dentre elas o prestígio; sendo que é a comunidade que elege suas lideranças. Contudo, os jesuítas passaram a intervir nestas hierarquias durante o período das reduções, pois procuravam lideranças que lhes apoiassem e não o contrário. Parece-nos que essa atitude vai contra os ensinamentos do ñande reko Guarani; por isso, essas lideranças solicitaram o auxílio das lideranças espirituais que, por intermédio das suas "ameaças", estavam demonstrando o que poderia ocorrer de ruim se eles continuassem seguindo os ensinamentos cristãos.

Em ambas as situações de contatos, os "rebeldes do Ibiá" e os Paye que estabeleceram relações guerreiras com estas reduções, ocorreu o estabelecimento de uma "fronteira" oriunda do "estranhamento cultural", gerando situações de conflitos, entre os grupos. É o caso de Tayubai e dos demais indígenas do Ibiá, que, ao se sentirem ameaçados pelos avanços do projeto jesuítico, atacaram o padre Mendonza. Em contrapartida, os indígenas reduzidos fazem o mesmo para recuperar o corpo do missionário.

No segundo caso, esse estranhamento cultural torna-se ainda mais visível, já que os próprios indígenas dos arredores das reduções teriam chamado os Paye para expulsar os jesuítas de seus territórios, pois não consideravam os seus ensinamentos adequados. E os missionários, sentindo-se "acuados" pelas ameaças destes "hechizeros", os levaram à força para as reduções com o intuito de "desmascará-los". 
A partir dessas situações, compreendemos que o ñande reko Guarani foi uma das fundamentações/estratégias para que estas lideranças justificassem, perante suas comunidades, o enfrentamento dos jesuítas inimigos e de seus aliados. Nesse contexto, é preciso compreender que há as disputas de poder entre as lideranças políticas e espirituais Guarani, sejam elas favoráveis ou contrárias ao Projeto da Companhia de Jesus, e os padres; portanto, os conflitos não ocorrem sem que cada um dos grupos envolvidos esteja defendendo seus interesses.

\section{Considerações finais}

Percebe-se, através das situações analisadas, que os Guarani foram sujeitos de sua história, realizando alianças ou deflagrando guerras aos jesuítas ou mesmo a suas próprias parcialidades, demonstrando assim que também foram protagonistas dos acontecimentos. As parcialidades que preferiram estar nas reduções realizaram as suas escolhas, mas nem por isso deixaram de posicionar-se favoráveis ou contrários aos padres. Barth (2000, p. 176) salienta que as ações de um mesmo grupo étnico não necessariamente precisam ser iguais, considerando que um evento pode ter diferentes interpretações, "[...] ou seja, podem viver juntos, mas em mundos diferentemente construídos".

Constata-se assim que cada parcialidade, seja a liderada por Tayubai e Apyçaire ou Antonio, Aryia, Caaobi, bem como, as demais, ao longo dos contatos com os missionários, realizaram suas próprias escolhas: aliar-se ou deflagrar guerras contra eles; entretanto, não deixaram de lado a sua lógica cultural, que estava prescrita. É claro que os padres exerceram forte pressão sobre esses sujeitos missionados, o que gerou ressignificações de elementos culturais, mas considerar que eles foram "aculturados" e que não tiveram voz dentro destes espaços é simplesmente ignorar a dinâmica cultural interna dos próprios Guarani. Ademais, é preciso compreender que os indígenas não permaneceram confinados nos espaços missionais ou mesmo doutrinados a todo o momento pelo cristianismo, uma vez que se movimentavam pelo território; portanto, sempre que desejassem, poderiam continuar a praticar o ñande reko.

Nos dois eventos analisados, evidencia-se a importância do papel das lideranças políticas (Tuvichá e Capitães) e espirituais (Karaí e Paye) nesta sociedade, pois elas tomavam a frente nas batalhas e possuíam a função de repassar, sobretudo aos mais jovens, os elementos culturais da tradição Guarani. Como demonstrado no primeiro evento, a incursão guerreira ao grupo do padre Mendonza foi uma resposta de Tayubai e das demais lideranças Tayabaiba (Karaí), Guinpi, Ñanduai, Tabeçaca, Yapepoyaca (Tuvichás) à presença do padre e do 
seu grupo em seus territórios, bem como, uma demonstração de vingança contra o fato ocorrido na redução de San Miguel. Portanto, "guerra" e "vingança", fundamentais para o ethos Guarani, são demonstrações da continuidade cultural indígena.

O segundo caso também evidencia como muitos Karaí, Paye e Tuvichá, a exemplo de Apyçaire, Guiaba, não estavam de acordo com a atuação dos missionários em seus territórios; por isso, atacaram as reduções. Por fim, constatou-se que estas lideranças espirituais, ao declararem guerra contra a presença e os ensinamentos dos jesuítas, também procuravam readquirir "prestígio" que a posição de Paye ou Karaí possibilita entre as parcialidades Guarani, visto que, com a chegada dos padres, aqueles haviam perdido "espaço".

\section{Referências}

ALMEIDA, Maria Regina Celestino de. Os índios na história do Brasil. Rio de Janeiro: FGV, 2010.

AVILM, Davis Moreira. A colônia imaginada: Anchieta e as metamorfoses do imaginário medieval na América portuguesa (1534-1597). 2004. 137 f. Dissertação (Mestrado em História) - Universidade Federal do Espírito Santo, Vitória, 2004.

BAPTISTA, Jean Tiago. Jesuítas e Guarani na pastoral do medo: as variáveis do discurso missionário sobre a natureza. 2004. Dissertação (Mestrado em História) - Pontifica Universidade Católica do Rio Grande do Sul, Porto Alegre, 2004.

BARTH, Fredrik. Por um maior naturalismo na conceptualização das sociedades. In: . O guru, o iniciador e outras variações antropológicas. Rio de Janeiro: Contra Capa, 2000. p. 168-186.

BECKER, Ítala Irene Basile. Lideranças indígenas: no começo das reduções jesuíticas da província do Paraguay. São Leopoldo: Instituto Anchietano de Pesquisas, 1992. (Antropologia, n. 47).

BRANDÃO, Carlos Rodrigues. Identidade e etnia: a construção da pessoa e a resistência cultural. São Paulo: Brasiliense, 1986.

BROCHADO, José Proenza. A expansão dos Tupi e da cerâmica da tradição policrômica amazônica. Revista do Museu de Arqueologia e Etnologia, São Paulo, p. 65-82, 1989. 
CARTA Ânua de 1635. In: CORTESÃO, Jaime (Org.). Jesuittas e bandeirantes no Tape (1615-1641). Rio de Janeiro: Biblioteca Nacional, 1969.

CASTRO, Eduardo Viveiros de. Xamanismo e sacrifício. In: CASTRO, Eduardo Viveiros. $A$ inconstância da alma selvagem: e outros ensaios de antropologia. São Paulo: Cosac \& Naify, 2002. p. 457-472.

CAVALCANTE, Thiago Leandro Vieira. Etno-história e história indígena: questões sobre conceitos, métodos e relevância da pesquisa. História, São Paulo, v. 30, n. 1, p. 349-371, jan./jun. 2011.

CHAMORRO, Graciela. Os Guarani, sua trajetória e seu modo de ser. São Leopoldo: Comin, 1999. (Cadernos).

CUNHA, Manuela Carneiro da. História dos índios no Brasil. 2. ed. São Paulo: Companhia das Letras, 1998.

GINZBURG, Carlo. História noturna. São Paulo: Companhia das Letras, 2012.

GRUZINSKI, Serge. O pensamento mestiço. São Paulo: Companhia das Letras, 2001.

LAROQUE, Luís Fernando da Silva et al. Etnohistória como abordagem interdisciplinar no estudo de populações indígenas Guarani. Boletim de Geografia, Maringá, v. 33, p. 168-183, 2015. Disponível em: $<$ http://www.periodicos.uem.br/ojs/index.php/BolGeogr/article/viewFile/22078/pdf_78>. Acesso em: 3 jun. 2016.

MAEDER, Ernesto J. A. Cartas anuas de la Provincia de Paraguay (1632-1634). Resistencia: Instituto de Investigaciones Geohistóricas, 1984.

MONTEIRO, John Manuel. Negros da terra: índios e bandeirantes nas origens de São Paulo. São Paulo: Companhia das Letras, 1994.

MONTOYA, Antonio Ruiz. Conquista espiritual hecha por los religiosos dela Compañia de Iesus, en lãs Provincias del Paraguay, Parana, Uruguay, y Tape. Madrid: En La Imprenta del Reyno, 1985.

MONTOYA, Antonio Ruiz. Tesoro de la lengua Guarani. Madrid: [s. n.], 1639. Disponível em: $<$ https://archive.org/stream/tesorodelalengua00ruiz\#page/n3/mode/2up>. Acesso em: 28 abr. 2016.

NOELLI, Francisco da Silva. Sem tekohá não há tekó: em busca de um modelo etnoarqueológico da aldeia e da subsistência Guarani e sua aplicação e uma área de domínio 
no delta do rio Jacuí-RS. 1993. 381 f. Dissertação (Mestrado em História) - Pontifica Universidade Católica do Rio Grande do Sul, Porto Alegre, 1993.

POMPA, Cristina. Profetas e santidades selvagens. Missionários e caraíbas no Brasil colonial. Revista Brasileira de História, São Paulo, v. 21, n. 40, p. 177-195, 2001.

PORTO, Aurélio. História das missões orientais e do Uruguai. Porto Alegre: Livraria Selbach, 1954.

PROENÇA, Thiago Iwaszko Marques. As marcas indígenas na região sócio-paisagísticas das terras baixas às margens do rio Caí. 2014. 123 f. Dissertação (Mestrado em Educação) Universidade Federal do Rio Grande do Sul, Porto Alegre, 2014.

RELLY, Eduardo; MACHADO, Neli Teresinha Galarce; SCHNEIDER, Patrícia. Do taiaçuapé a colinas. Lajeado: Univates, 2008.

ROGGE, Jairo Henrique. Fenômenos de fronteira: um estudo das situações de contato entre os portadores das tradições cerâmicas pré-históricas no Rio Grande do Sul. 2004. 241 f. Tese (Doutorado em História) - Universidade do Vale do Rio dos Sinos, São Leopoldo, 2004.

SAHLINS, Marshall. Ilhas de história. Rio de Janeiro: Jorge Zahar, 1990.

SOARES, André Luis Ramos. Guarani: organização social e arqueologia. Porto Alegre: Edipucrs, 1997.

URBAN, Greg. A história da cultura brasileira segundo as línguas nativas. In: CUNHA, Manuela Carneiro (Org.). História dos índios do Brasil. São Paulo: Companhia das Letras, 1992. p. 87-102.

WEIRICH, Alex. Índios e brancos no Vale do Taquari durante os séculos XVI e XVII. 2006. $74 \mathrm{f}$. Trabalho de Conclusão de Curso (Graduação em História) - Centro Universitário Univates, Lajeado, 2006. 